\title{
Research Trends from 2010 to 2020 for Pain Treatment with Acupuncture: A Bibliometric Analysis
} This article was published in the following Dove Press journal:
Journal of Pain Research

Background: Given that acupuncture treatment for pain has gradually been accepted by researchers from various countries. However, few bibliometric analyses have been performed on the published articles. The objective of this research was to review its application for pain in recent 10 years and analyze, demonstrate and evaluate the trends, major research hotspots and frontier areas.

Methods: The Web of Science retrieved literature from 2010 to 2020 on acupuncture for pain. The CiteSpace and Excel were used to analyze annual volumes of publications, journals, cited journals, countries, institutions, authors, cited authors, references and keywords and to draw collaborative networks and reference co-citation network maps.

Results: The search finally included 4227 related studies. Results show that the number of annual publications has been increasing gradually. Evid Based Complement Alternat Med (366) was the most productive journal, while Pain (2270/0.04) ranked first in terms of frequency and centrality of cited journals, respectively. Among countries/institutions, the China (1252) and the Kyung Hee University (228) ranked first. Lee MS (51 articles) was the most effective author while MacPherson H (577) was the most cited author. The most frequently cited reference was a systematic review of individual patient data on acupuncture for chronic pain (322). "Burden" was identified as a frontier research item for 2017-2020.

Conclusion: This study provides a new and in-depth understanding of current acupuncture used for the treatment of pain. We anticipate that this study will stimulate international cooperation among research teams to advance the field.

Keywords: acupuncture, pain, CiteSpace, co-citation analysis, co-occurrence analysis

\section{Introduction}

Pain is an unpleasant sensory and emotional perception associated with actual or underlying tissue pathology. It has become an important healthcare and social problem for its high incidence, great influence on quality of life and high medical costs. It was estimated that more than $20 \%$ of the population visit the clinic with pain as the main complaint every year. ${ }^{1,2}$ Studies have shown that patients with pain are at risk for illness absenteeism and poor health-related quality of life. An assessment of health care spending in the United States estimates that the annual cost of treating pain is $\$ 635$ billion. $^{3}$

Due to the complex cause and recurrent symptom, the targets of treatment options for pain are poor. As the most commonly used treatment, medicine (eg, muscle relaxants and non-steroidal anti-inflammatory drugs) can quickly alleviate
Correspondence: Lai-Xi Ji

Shanxi University of Traditional Chinese

Medicine, Taiyuan, Shanxi, People's

Republic of China

Tel +86 I35097। 4277

Email tyjilaixi@I26.com
Journal of Pain Research 2021:14 94I-952

941

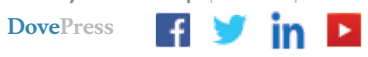

http://doi.org/| 0.21 47/|JPR.S30091/ 
acute pain, but its side effects can not be ignored. ${ }^{4}$ So seeking for effective complementary and alternative therapies (C\&AT) attracts both patients and practitioners. Acupuncture, as a component of traditional Chinese medicine, has been extensively used in the treatment of pain for more than 3000 years, and hundreds of clinical and experimental studies were published during the last decade, it is a need for reviewing the study status to provide the reference for future studies. This study aims to scientifically collect the literature of acupuncture for pain from 2010 to 2020, including clinical research and animal experiments, review the research status, analyze the research trends and hot spots, and explore the potential problems in this field, so as to promote future research and clinical application.

\section{Methods}

\section{Data Acquisition}

In this study, we adopted the Web of Science core collection database as our database because it provided references that have been compiled according to the requirements of CiteSpace software for formatting references used for co-citation analysis. Web of Science also has a wide range of references, which may have higher citation rates. Therefore, this database was appropriate for our study.

We selected a core collection of databases from the Web of Science for studies on acupuncture for pain. The data search strategy included the topic "acupuncture" and "pain", with the publication period of the literature ranging from 2010 to 2020 . We excluded articles that could not be obtained as full texts and repeated publications. There were no restrictions on language, type of document and type of research including interventions, mechanisms, diagnosis, and other related studies.

\section{Analysis Tool}

We used CiteSpace 5.6 and Excel 2019 to analyze data for articles used in the study. Our analysis included the following: (1) descriptive statistical analysis, descriptive analysis of the annual publication volume, journals, countries, institutions, authors, references, and keywords; (2) cooccurrence analysis, a co-occurrence map for countries, institutions, author cooperation networks, keywords and burst keywords was drawn. A cooperative analysis of institutions and authors was based on all authors, and the section of cited authors was extracted by the first author for analysis. Keywords were analyzed by extracting keywords listed in selected articles. We directly analyzed the original keywords in the data set and supplementary keywords in the database; (3) cluster analysis which involved clustering co-citations of articles to investigate changes in research topics over time.

\section{Quality Control}

Research quality was controlled through the following methods: (1) formulation of strict search terms to ensure recall rate, (2) research results for the final knowledge map were confirmed by experts in relevant fields to verify guidance of research conclusions for clinical practice.

\section{Results}

\section{Analysis of Annual Publications}

A total of 4227 articles were used in this study. The number of articles published each year is shown in Figure 1. The number of articles published increased from 292 in 2010 to 442 in 2020, indicating that the number of publications is increasing but fluctuating.

\section{Analysis of Journals and Cited Journals Analysis of Journals}

The number of journals that published 4227 articles on acupuncture treatment for pain was 850 . The ten most active journals are listed in Table 1 and publishers of these journals were mostly located in the United States or England. Most of the articles were published in the Journal of Evidence-Based Complementary and Alternative Medicine (Evid Based Complement Alternat Med), followed by the Journal of Acupuncture in Medicine (Acupunct Med) and the Journal of Alternative and Complementary Medicine (J Altern Complem Med). Furthermore, we found that the Cochrane Database of Systematic Reviews (CDSR) with the highest IF is a leading journal and database for systematic reviews in health care, with an IF of 7.89 .

\section{Analysis of Cited Journals}

The analysis of co-citation of journals indicates a distribution of significant knowledge sources in a particular field. Results of our statistical analysis revealed that the total number of journals that published articles on acupuncture treatment for pain was 963. The most frequently cited journals were Pain, followed by the Journal of Alternative and Complementary Medicine ( $J$ Altern Complem Med), Evid-based Compl Alt (Tables 2 and 3). In 


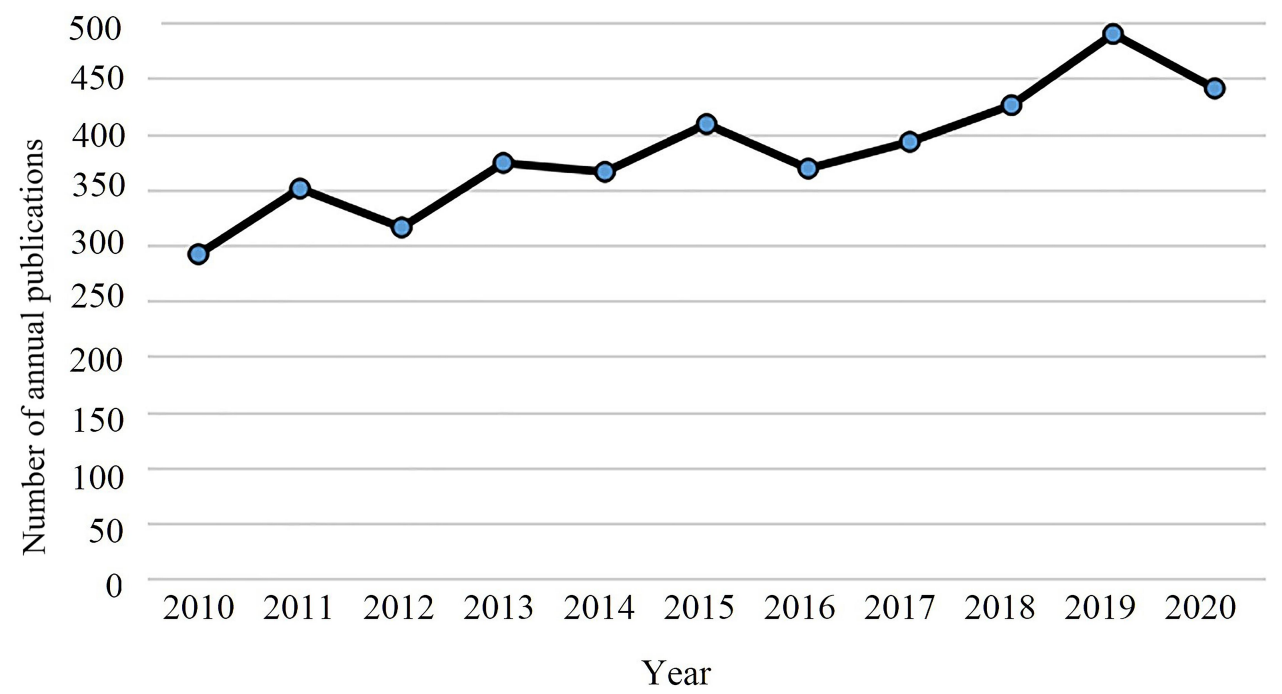

Figure I The number of acupuncture treatment for pain publications from 2010 to 2020 .

terms of centrality, the top 5 journals were: Pain, Journal of Neuroscience (J Neurosci), Journal of Applied Physiology ( Appl Physiol), Journal of Advanced Nursing (J Adv Nurs) and Brain Research.

Table I The Top 10 Journals with the Highest Frequency of Acupuncture Treatment for Pain

\begin{tabular}{|c|c|c|c|c|}
\hline Ranking & Frequency & Journal $^{\mathbf{a}}$ & $\begin{array}{c}\text { IF } \\
2019^{b}\end{array}$ & Country \\
\hline I & 366 & $\begin{array}{l}\text { Evid-based Compl } \\
\text { Alt }\end{array}$ & 1.813 & $\begin{array}{l}\text { United } \\
\text { States }\end{array}$ \\
\hline 2 & 238 & Acupunct Med & 2.129 & England \\
\hline 3 & 162 & $\begin{array}{c}\text { J Altern Complem } \\
\text { Med }\end{array}$ & 2.109 & $\begin{array}{l}\text { United } \\
\text { States }\end{array}$ \\
\hline 4 & 148 & Medicine & 1.552 & $\begin{array}{l}\text { United } \\
\text { States }\end{array}$ \\
\hline 5 & 117 & Trials & 1.883 & England \\
\hline 6 & 95 & $\begin{array}{c}\text { Complement Ther } \\
\text { Med }\end{array}$ & 2.063 & England \\
\hline 7 & 88 & $\begin{array}{c}\text { BMC Complement } \\
\text { Altern Med }\end{array}$ & 2.833 & England \\
\hline 8 & 73 & Plos One & 2.74 & $\begin{array}{l}\text { United } \\
\text { States }\end{array}$ \\
\hline 9 & 65 & $\begin{array}{c}\text { Cochrane Db Syst } \\
\operatorname{Rev}\end{array}$ & 7.89 & England \\
\hline 10 & 65 & Eur J Integr Med & 0.974 & Germany \\
\hline
\end{tabular}

Notes: ajournal names according to Index of Medical Journal Abbreviations; ${ }^{\mathrm{I} I F}$ in category according to Journal Citation Reports (2019).

Abbreviation: IF, impact factor.

\section{Analysis of Countries}

We used CiteSpace to generate a map of countries with 85 nodes and 369 links. The size of nodes in the cooperation graph indicated the number of articles published by a country, and the links between nodes represented the strength and time of the cooperative relationship (Table 4 and Figure 2). A total of 4227 articles on acupuncture treatment for pain have been published in 85 countries. The top 5 countries have published 3457 articles, constituting $81.78 \%$ of the total publications. The China accounted for $29.62 \%(1252 / 4227)$ of the total publications, followed by the United States (27.04\%), South Korea (10.39\%), England (8.75\%) and Germany (5.98\%).

Table 2 The Top 5 Cited Journals with the Highest Frequency of Acupuncture Treatment for Pain

\begin{tabular}{|l|c|c|c|c|}
\hline Ranking & Frequency & Cited Journal $^{\mathbf{a}}$ & $\begin{array}{c}\text { IF } \\
\mathbf{2 0 1 9}^{\mathbf{b}}\end{array}$ & Country \\
\hline 1 & 2270 & Pain & 5.483 & $\begin{array}{c}\text { United } \\
\text { States }\end{array}$ \\
\hline 2 & 1669 & $\begin{array}{c}\text { J Altern Complem } \\
\text { Med }\end{array}$ & 2.109 & $\begin{array}{c}\text { United } \\
\text { States }\end{array}$ \\
\hline 3 & 1613 & $\begin{array}{c}\text { Evid-based Compl } \\
\text { Alt }\end{array}$ & 1.813 & $\begin{array}{c}\text { United } \\
\text { States }\end{array}$ \\
\hline 4 & 1585 & Acupunct Med & 2.129 & England \\
\hline 5 & 1368 & $\begin{array}{c}\text { Cochrane Db Syst } \\
\text { Rev }\end{array}$ & 7.89 & England \\
\hline
\end{tabular}

Notes: ajournal names according to Index of Medical Journal Abbreviations; ' $\mathrm{I} F$ in category according to Journal Citation Reports (2019).

Abbreviation: IF, impact factor. 
Table 3 Top 5 Cited Journals with the Highest Centrality Associated with Acupuncture Treatment for Pain

\begin{tabular}{|l|c|c|c|c|}
\hline Ranking & Centrality & $\begin{array}{c}\text { Cited } \\
\text { Journal }\end{array}$ & $\begin{array}{c}\text { IF } \\
\mathbf{2 0 1 9}^{\mathbf{b}}\end{array}$ & Country \\
\hline I & 0.04 & Pain & 5.483 & $\begin{array}{l}\text { United } \\
\text { States }\end{array}$ \\
\hline 2 & 0.03 & J Neurosci & 5.673 & $\begin{array}{l}\text { United } \\
\text { States }\end{array}$ \\
\hline 3 & 0.03 & J Appl Physiol & 3.044 & $\begin{array}{l}\text { United } \\
\text { States }\end{array}$ \\
\hline 4 & 0.03 & J Adv Nurs & $2.56 \mathrm{I}$ & England \\
\hline 5 & 0.02 & Brain Res & 2.733 & Netherlands \\
\hline
\end{tabular}

Notes: ${ }^{a}$ Journal names according to Index of Medical Journal Abbreviations; ' $\mathrm{IF}$ in category according to Journal Citation Reports (2019).

Abbreviation: IF, impact factor.

The top five countries with centrality were the United States (0.46), England (0.27), China (0.16), Italy (0.12) and Germany (0.09).

\section{Analysis of Institutions}

We used CiteSpace to generate agency maps with 457 nodes and 1950 links. Agency maps indicated that the 4227 articles were submitted by 457 scientific research institutions. The top 5 institutions based on the number of publications included: Kyung Hee University (5.39\%), Beijing University Chinese Medicine (3.24\%), Chinese Academy of Chinese Medical Sciences (3.10\%), Korea Institute of Oriental Medicine (2.82\%) and China Medical University (2.77\%) (Table 5 and Figure 3). The top 5 institutions in centrality were Kyung Hee University, University of Maryland, China Medical University, Harvard university and Beijing University Chinese Medicine.

\section{Analysis of Authors}

CiteSpace software was used to generate a co-authors map showing 565 nodes and 1675 links. The size of nodes in the cooperation graph represented the number of articles published by an author, and the link between them reflected the strength of their cooperative relationship
(Table 6 and Figure 4). A total of 4227 articles were published by 565 authors. Lee MS was the most active author in this research field with 51 articles, followed by Liang FR (49 articles) and MacPherson H (48 articles).

\section{Analysis of Cited Author}

CiteSpace was used to generate a co-authors map displaying 853 nodes and 6914 links. The size of nodes represented the number of author citations and the link between them indicated the strength of co-citation (Table 7). The top 5 most cited authors were MacPherson H (577), Han JS (534), Vickers AJ (500), Linde K (420), and Ernst E (383). The top 5 authors in centrality were Kong J, Itoh K, Cherkin DC, Lund Irene, and White P.

\section{Analysis of Cited Reference}

Co-citation implies that two articles appear together in the reference list of a third cited article thus the two articles form a co-citation relationship. Co-citation suggests that the cited literature and corresponding research are related in content, and the literature usually contains high-quality content which has significant influence in a particular field of research. Moreover, the relationship between literature co-citation is likely to change with time. Study of the network for literature co-citation can facilitate investigation of the developments and evolution in a specific discipline. A total of 99,873 reference articles were extracted from the 4227 articles to analyze cited references. We considered 2010 to 2020 as our time span and a time slice of 1. Fifty most frequently cited or items which appeared were selected from each time slice to form a network diagram of cited references comprising 925 nodes and 5029 links. An analysis in terms of cocitation counts and centrality (Tables 8 and 9) revealed that the data on this topic over the past decade are generally in the form of 1) randomized trials, 2) meta-analysis, 3) research on the mechanism of acupuncture analgesia, and 4) placebo effect of acupuncture..$^{5-13}$

Table 4 Top 5 Countries Related to Acupuncture Treatment for Pain

\begin{tabular}{|l|c|c|c|c|c|}
\hline Ranking & Frequency & Country & Ranking & Centrality & Country \\
\hline $\mathrm{I}$ & 1252 & China & 1 & 0.46 & United States \\
2 & 1143 & United States & 2 & 0.27 & England \\
3 & 439 & South Korea & 3 & 0.16 & China \\
4 & 370 & England & 4 & 0.12 & Italy \\
5 & 253 & Germany & 5 & 0.09 & Germany \\
\hline
\end{tabular}




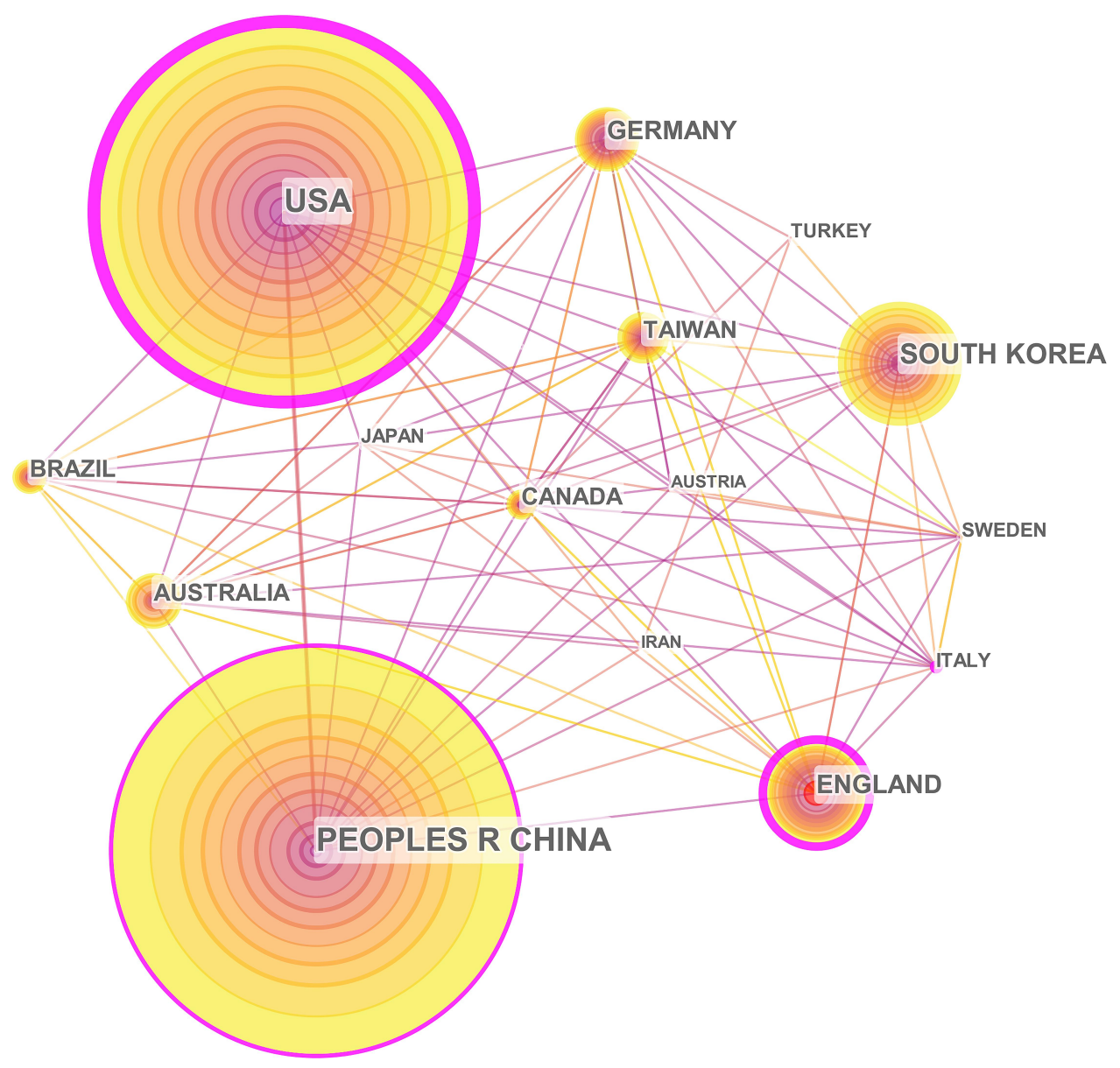

Figure 2 A country cooperation map related to acupuncture treatment for pain research from 2010 to 2020.

We applied a logarithmic likelihood ratio (LLR) algorithm to assess nominal terms extracted from the keyword list of articles to naming of clusters to explore research models and emerging trends in knowledge systems, and to obtain key information from cited references. Seventeen clusters were generated with a modularity value of 0.6822 , indicating that clustering results were highly reliable (Figure 5). Silhouette was 0.3321, implying that the resulting network community structure was significant. Results proved that our cluster was reasonable. We have listed the first 8 clusters with the largest scale, and the number of articles represented the importance of the clustering domain obtained. The largest group was "placebo effect", which consisted of 109 reference articles. Cluster \# 4 "knee osteoarthritis" was drawn using cold colors to indicate that it was a new research direction that had recently emerged.

\section{Analysis of Co-Occurrence Keywords}

Research frontiers can be identified by analyzing keywords. A keyword co-occurrence network containing 624 nodes and 6508 links was generated. Table 10 and Figure 6 represent

Table 5 Top 5 Institutions Related to Acupuncture Treatment for Pain

\begin{tabular}{|c|c|c|c|c|c|}
\hline Ranking & Frequency & Institution & Ranking & Centrality & Institution \\
\hline 1 & 228 & Kyung Hee University & I & 0.2 & Kyung Hee University \\
\hline 2 & 137 & Beijing University Chinese Medicine & 2 & 0.19 & University of Maryland \\
\hline 3 & $|3|$ & Chinese Academy of Chinese Medical Sciences & 3 & 0.17 & China Medical University \\
\hline 4 & 119 & Korea Institute of Oriental Medicine & 4 & 0.14 & Harvard university \\
\hline 5 & 117 & China Medical University & 5 & 0.13 & Beijing University Chinese Medicine \\
\hline
\end{tabular}




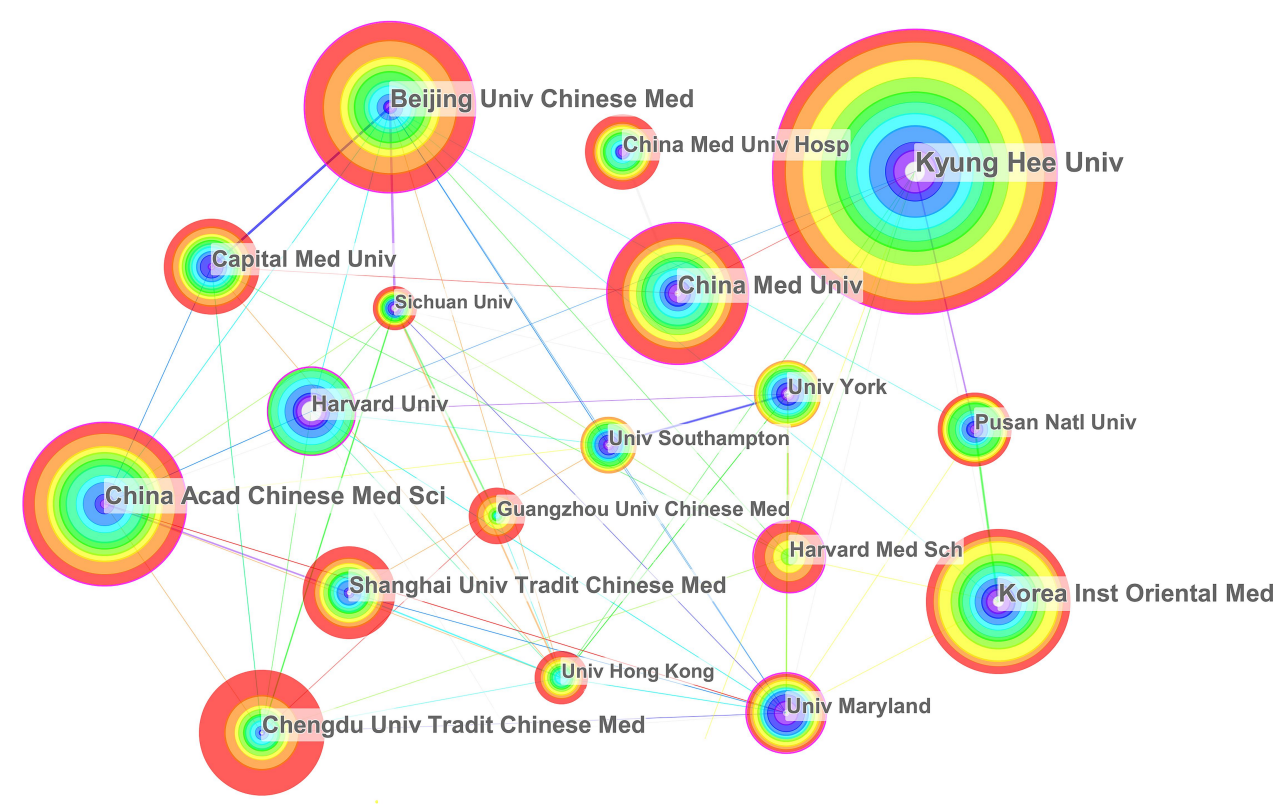

Figure 3 An institution cooperation map related to acupuncture treatment for pain research from 2010 to 2020 .

a network of co-occurring keywords with high frequencies; the larger the character, the higher the frequency of the keyword. The most widely used keywords related to acupuncture treatment for pain over the last few years were "acupuncture", "pain" and "electroacupuncture".

\section{Analysis of Burst Keywords}

Burst keywords were automatically generated by the software based on the keywords in the list, used to record a keyword that changes greatly within a short period of time. It is considered to be another crucial indicator of

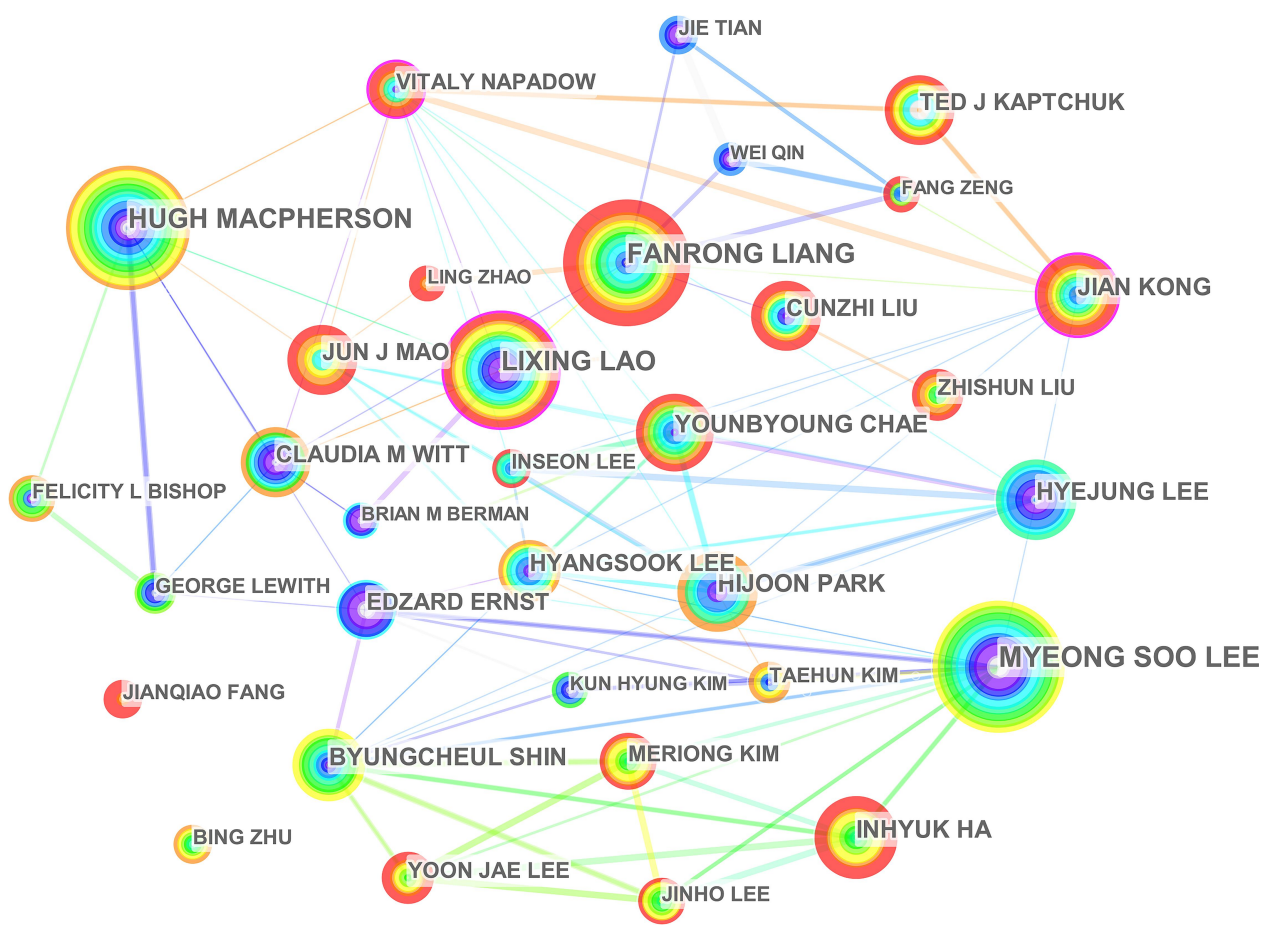

Figure 4 A coauthor map related to acupuncture treatment for pain research from 2010 to 2020 . 
Table 6 Top 5 Active Authors Related to Acupuncture Treatment for Pain

\begin{tabular}{|l|c|c|c|c|c|}
\hline Ranking & Frequency & Author & Ranking & Centrality & Author \\
\hline 1 & $5 I$ & Lee MS & 1 & 0.12 & Lao LX \\
2 & 49 & Liang FR & 2 & 0.1 I & Napadow V \\
3 & 48 & MacPherson H & 3 & 0.11 & Kong J \\
4 & 44 & Lao LX & 4 & 0.09 & Liu JP \\
5 & 32 & Ha IN & 5 & 0.08 & MacPherson H \\
\hline
\end{tabular}

Table 7 Top 5 Cited Authors Related to Acupuncture Treatment for Pain

\begin{tabular}{|l|c|c|c|c|c|}
\hline Ranking & Frequency & Cited Author & Ranking & Centrality & Cited Author \\
\hline I & 577 & MacPherson H & 1 & 0.07 & Kong J \\
2 & 534 & Han JS & 2 & 0.05 & Itoh K \\
3 & 500 & Vickers AJ & 3 & 0.05 & Cherkin DC \\
4 & 420 & Linde K & 4 & 0.05 & Lund Irene \\
5 & 383 & Ernst E & 5 & 0.04 & White P \\
\hline
\end{tabular}

research hotspots or future trends. The top 20 keywords that were frequently cited over time are presented in Figure 7.

\section{Discussion}

To the best of our knowledge, this is the first bibliometric study of acupuncture for pain management. In this study, we retrieved data from 4227 studies investigating the application of acupuncture for pain, published between 2010 and 2020. Data from these studies were analyzed using CiteSpace and Excel employing descriptive statistical, co-occurrence and cluster analyses.

\section{General Information}

We found a general increasing trend in acupuncture for pain publications from 2010 to 2020 . The trend of increase in articles published can be divided into the following three stages: (1) the number of articles increased rapidly in 2010, reaching a first slight peak, and then declined in 2012; (2) number of articles increased steadily from 2012 to 2015, and decreased from 2015 to 2016; (3) the period from 2016 to 2019 was a rapid development period and reached a second peak in 2019. This trend was consistent with that observed in other research fields and can be well explained by the increased attention of researchers in this field. $^{14}$

The top 10 academic journals published 1417 articles, accounting for $33.52 \%$ of all articles and suggesting that these top 10 journals had strong interest in articles regarding acupuncture treatment for pain research. According to the analysis of the cited journals, the top ranking for both frequency and centrality was

Table 8 The Top 5 Cited References for the Highest Frequency of Acupuncture Treatment for Pain

\begin{tabular}{|l|c|l|c|}
\hline Ranking & Frequency & Cited Reference & $\begin{array}{c}\text { Representative Author } \\
\text { (Publication Year) }\end{array}$ \\
\hline 1 & 322 & Acupuncture for chronic pain: individual patient data meta-analysis & ${\text { Vickers }(2012)^{5}}^{5}$ \\
\hline 2 & 165 & Neural mechanism underlying acupuncture analgesia & ${\text { Zhao }(2008)^{6}}^{\text {Hake }^{2}(2007)^{7}}$ \\
\hline 3 & 142 & $\begin{array}{l}\text { German Acupuncture Trials (GERAC) for chronic low back pain: randomized, } \\
\text { multicenter, blinded, parallel-group trial with 3 groups }\end{array}$ & Zhang (2014) $^{8}$ \\
\hline 5 & 124 & Mechanisms of acupuncture-electroacupuncture on persistent pain & Cherkin (2009) $^{9}$ \\
\hline
\end{tabular}


Table 9 The Top 5 Cited References for the Highest Centrality of Acupuncture Treatment for Pain

\begin{tabular}{|l|c|l|c|}
\hline Ranking & Centrality & Cited Reference & $\begin{array}{c}\text { Representative Author } \\
\text { (Publication Year) }\end{array}$ \\
\hline I & 0.11 & $\begin{array}{l}\text { German Randomized Acupuncture Trial for chronic shoulder pain (GRASP) - } \\
\text { a pragmatic, controlled, patient-blinded, multi-centre trial in an outpatient care } \\
\text { environment }\end{array}$ & Molsberger (20I0) $^{10}$ \\
\hline 2 & 0.07 & $\begin{array}{l}\text { Traditional Chinese acupuncture and placebo (sham) acupuncture are differentiated by } \\
\text { their effects on mu-opioid receptors (MORs) } \\
\text { Effectiveness of dry needling for upper-quarter myofascial pain: a systematic review and } \\
\text { meta-analysis }\end{array}$ & Kietrys (20I3) \\
\hline 3 & 0.07 & Acupuncture for acute low back pain: a systematic review & Lee (2009) \\
\hline 5 & 0.07 & $\begin{array}{l}\text { The effectiveness of acupuncture in treating chronic non-specific low back pain: } \\
\text { a systematic review of the literature }\end{array}$ & Hutchinson (20I2) \\
\hline
\end{tabular}

Pain. A systematic review of available therapies for hip and knee osteoarthritis patients, which cited an article in the Pain journal was cited 942 times. This study updates the evidence to suggest that non-pharmacological therapies, including acupuncture, are effective in relieving patients' pain symptoms. ${ }^{15}$ We established that most of these journals are relevant to complementary alternative therapies and pain research. These data will help future scholars to select appropriate journals when submitting articles in related fields.

Less collaborations were observed between countries/regions. Asia, as the birthplace of acupuncture, and developed countries, including the United States, were the main research forces related to acupuncture for the treatment of pain, suggesting that scientific research development is inseparable from economic conditions and academic atmosphere. However, global cooperation has not been formed. Cooperation among other countries was weak except for England where scientific cooperation was relatively close in recent years. This may be attributed to the geographical location of countries. Regarding institutions, it is interesting that Kyung Hee University was not only the most prolific institution but also the highest centrality institution, suggesting that Kyung Hee University is the most important institution for researching acupuncture

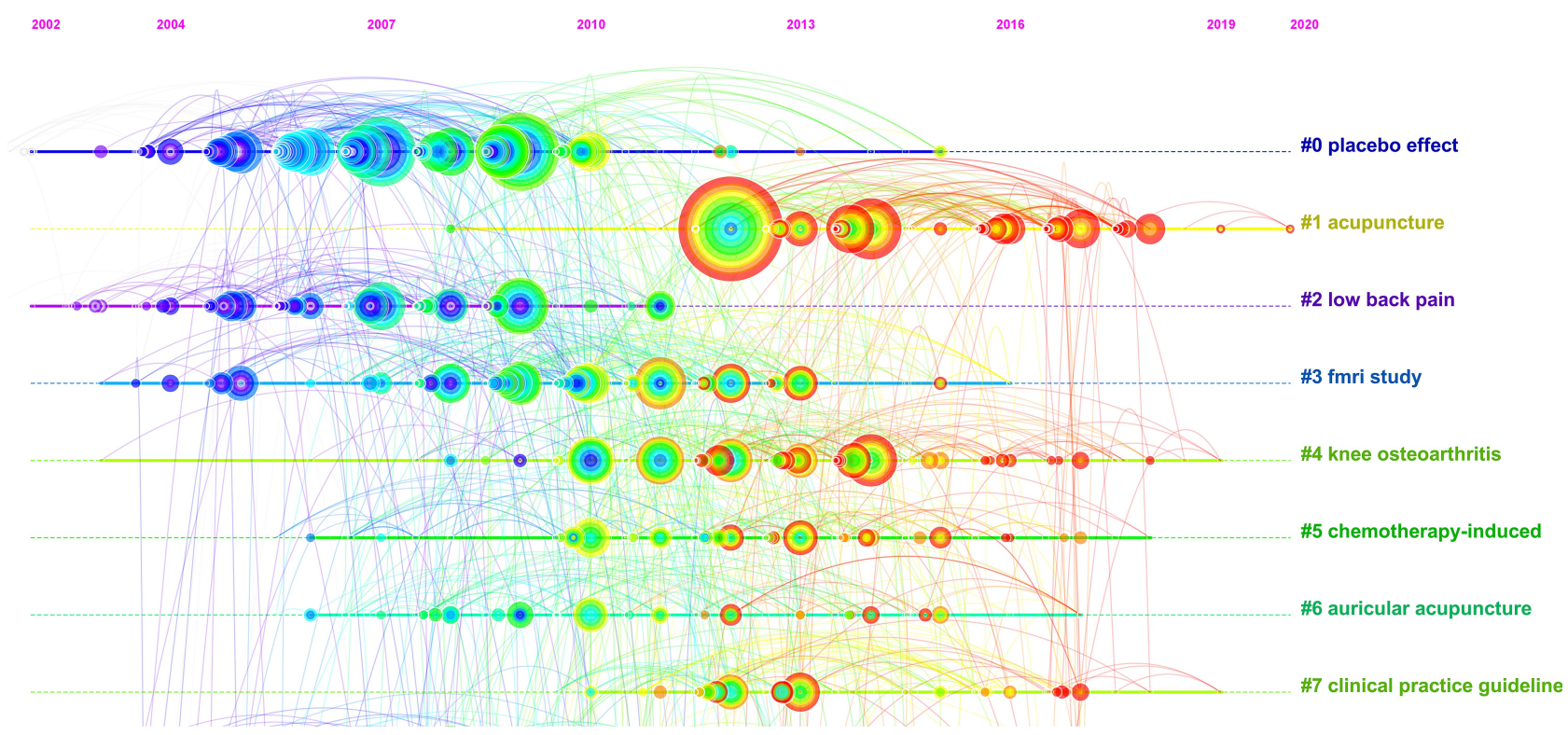

Figure 5 Reference cocitation map related to acupuncture treatment for pain research from 2010 to 2020. 
Table 10 Top 10 Keywords Related to Acupuncture Treatment for Pain

\begin{tabular}{|l|c|c|c|c|c|}
\hline Ranking & Frequency & Keyword & Ranking & Centrality & Keyword \\
\hline 1 & 2206 & Acupuncture & 1 & 0.03 & Complementary and alternative medicine \\
2 & 1290 & Pain & 2 & 0.03 & Disorder \\
3 & 621 & Electroacupuncture & 3 & 0.03 & Myofascial pain \\
4 & 577 & Management & 4 & 0.03 & Acupuncture analgesia \\
5 & 490 & Low back pain & 5 & 0.03 & Randomized trial \\
6 & 418 & Randomized controlled trial & 6 & 0.03 & Expectancy \\
7 & 358 & Therapy & 7 & 0.03 & Integrative medicine \\
8 & 285 & Mechanism & 8 & 0.03 & Inflammation \\
9 & 276 & Efficacy & 9 & 0.03 & Risk factor \\
10 & 275 & Prevalence & 10 & 0.03 & Acupuncture treatment \\
\hline
\end{tabular}

treatment of pain. However, England and Germany, the top 5 countries with the highest number of publications, did not have any institution in the top 10 list. This may indicate that institutions conducting research in this field are relatively few in the country. In addition, cooperation among institutions was mostly limited to countries such as Beijing University Chinese Medicine, China Medical University and Chinese Academy of Chinese Medical Sciences which were among the top 5 institutions. The close cooperation between China scientific research institutions in recent years may also be one of the reasons for the increase in the number of articles published each year.

All of the top 5 active authors published at least 30 articles. A study conducted by Ernst et al, cited 101 times, suggested that apart from neck pain, there is little convincing evidence that acupuncture is effective in reducing pain. ${ }^{16}$ However, Zhang et al proposed that electroacupuncture combined with low dosages conventional analgesics can provide effective pain control. ${ }^{8}$ In addition, cooperative relationships among authors are largely confined to their respective institutions. This demonstrates that several authors tend to work with stable

$$
\begin{aligned}
& \text { guideline reliability } \\
& \text { anxiety quality of life } \begin{array}{r}
\text { questionnaire } \\
\text { risk factor }
\end{array} \\
& \text { multicenter } \\
& \text { outcm } \\
& \begin{array}{ccc}
\text { model } & \text { efficacy } & \text { therapy validation } \\
\text { modulation } & \text { intervention expectancy } & \text { integrative medicine surgery }
\end{array} \\
& \begin{array}{c}
\text { symptom safety acupuncture treatment } \\
\text { fmri mechanism acupuncture placebo sham acupuncture }
\end{array} \\
& \text { brain electroacupuncture metaanalysis } \\
& \begin{array}{c}
\text { management protocol systematic review } \\
\text { neuropathic pain migraine } \\
\text { stimulation musculoskeletal pain inflammation }
\end{array} \\
& \text { rheumatoid arthriti pain neck pain acupressure massage hyperalgesia } \\
& \text { chronic pain low back pain auricular acupuncture massage } \\
& \text { knee osteoarthriti prevalence complementary and alternative medicine } \\
& \text { shoulder pain diagnosis trigger point electrical nerve stimulation } \\
& \text { postoperative pain randomized trial double blind } \\
& \text { disorder physiotherapy myofascial pain } \\
& \text { osteoarthriti breast cancer acupuncture analgesia } \\
& \text { irritable bowel syndrome follow up } \\
& \text { exercise receptor }
\end{aligned}
$$

Figure 6 Keyword co-occurrence map related to acupuncture treatment for pain research from 2010 to 2020. 


\section{Top 20 Keywords with the Strongest Citation Bursts}

Keywords
acupuncture analgesia
human brain
burden
human
placebo needle
electrical stimulation
system
nitric oxide
pelvic pain
antinociception
qi
neck
cam
spinal cord injury
analgesia
morphine
randomized trial
randomized controlled trials
framework
apipuncture

acupuncture analgesia

human

placebo needle

system

antinociception

cam

analgesia

morphine

randomized controlled trials as topic 2010

apipuncture

\begin{tabular}{lrl}
\multicolumn{4}{c}{ Year Strength Begin End $\mathbf{2 0 1 0}-\mathbf{2 0 2 0}$} \\
$2010 \quad \mathbf{9 . 5 9 6 1} 2010$ & 2014 \\
2010 & $\mathbf{8 . 3 0 4 7} 2010$ & 2014 \\
2010 & $\mathbf{7 . 4 6 7 1} 2017$ & 2020 \\
2010 & $\mathbf{7 . 4 2 7 9} 2012$ & 2016 \\
2010 & $\mathbf{7 . 1 2 6 4} 2010$ & 2012 \\
2010 & $\mathbf{6 . 5 5 7 8} 2010$ & 2011 \\
2010 & $\mathbf{6 . 2 5 1 7} 2010$ & 2011 \\
2010 & $\mathbf{6 . 1 2 8 3} 2015$ & 2016 \\
2010 & $\mathbf{6 . 1 0 1 3} 2016$ & 2018 \\
2010 & $\mathbf{5 . 9 8 8 1} 2010$ & 2012 \\
2010 & $\mathbf{5 . 8 5 4 1} 2010$ & 2013 \\
2010 & $\mathbf{5 . 7 8 7 6} 2012$ & 2016 \\
2010 & $\mathbf{5 . 6 5 1 4} 2011$ & 2015 \\
2010 & $\mathbf{5 . 4 3 4 4} 2015$ & 2016 \\
2010 & $\mathbf{5 . 3 4 4} 2011$ & 2012 \\
\hline 2010 & $\mathbf{5 . 2 4 1 1} 2016$ & 2018 \\
2010 & $\mathbf{5 . 1 7 4} 2011$ & 2012 \\
\hline
\end{tabular}

Figure 7 Top 20 keywords with the strongest citation bursts.

collaborative teams, and that cooperative networks for researchers in this field are highly correlated with the cooperative networks of corresponding institutions. Considering the co-cited authors, the top 5 authors with at least 383 co-citations made significant contributions to the field of acupuncture analgesia. A comprehensive analysis found that MacPherson $\mathrm{H}$ and Kong J were "core strength" researchers and their research had an important influence on the development of acupuncture treatment of pain. MacPherson $\mathrm{H}$ is mainly engaged in the evaluation of the effectiveness and safety of acupuncture, and the neuroimaging research on the mechanism of acupuncture. In 2010, MacPherson H and colleagues present an updated reporting guideline, which stands for Revised Standards for Reporting Interventions in Clinical Trials of Acupuncture. ${ }^{17}$ Kong $\mathrm{J}$ mainly focuses on the research of acupuncture analgesia. For example, a study in 2020 identified the neural marker of functional magnetic resonance imaging-based migraine and examined its association with acupuncture treatment. ${ }^{18}$

\section{Research Hotspots}

Co-citation suggests that the cited literature and corresponding research are related in content, and the literature usually contains high-quality content which has significant influence in a particular field of research. Moreover, the relationship between literature co-citation is likely to change with time.
The top 1 reference by frequency is a meta-analysis of individual patient data on acupuncture for chronic pain, which confirms the effectiveness of acupuncture for back and neck pain, osteoarthritis, chronic headache, and shoulder pain. ${ }^{5}$ The top 1 reference by centrality is a randomized controlled trial of acupuncture for chronic shoulder pain, indicating that acupuncture is an effective alternative to conventional orthopedic treatment for this condition. ${ }^{10}$ In addition, the extracted terms according to the LLR algorithm emphasize research characteristics and can provide the best results in terms of uniqueness and coverage of cluster-related topics. Cluster \# 4 knee osteoarthritis was discovered as a research hotspot of researchers in recent years. For example, Tu et al assessed the efficacy of intensive acupuncture ( 3 times weekly for 8 weeks) versus sham acupuncture for knee osteoarthritis (KOA) in 2020, based on their previous discussion of the efficacy of acupuncture at different frequencies in the treatment of KOA. ${ }^{19}$

Through analysing the keyword, research frontiers could be identified. Consistent with previous reports, "low back pain" in the current study is the most common pain disorder that uses acupuncture as an intervention. "Randomized controlled trial" was the most common research method with the strongest level of evidence to prove its efficacy. However, due to the particularity of the acupuncture operation, doubleblinding is difficult to achieve; therefore, the placebo effect has attracted the attention of researchers, and this finding is 
consistent with our findings in the cited reference. In addition, a burst keyword can indicate cutting-edge research topics and reveal studies that have potential or are of interest. Research history of acupuncture treatment of pain can be drawn from the evolution of keywords used in these articles. For example, "human brain" and "placebo needle" were the earliest words to have an impact, while "burden" was widely carried out in 2017 and has since been used.

\section{Strengths and Limitations}

This study has used bibliometrics for the first time to perform a visual analysis of literature related to acupuncture for pain, summarized research status and key research forces in this field, and predicted the research trend. In addition, we have used a variety of methods to analyze data, which is suitable for multi-angle interpretation of conclusions. However, this study has limitations that need to be addressed. This study only analyzed the core collection database for Web of Science, because CiteSpace is currently unable to analyze cited references for other databases. It is anticipated that the improvement of this software will enable the expansion of the selection range for databases in the future.

\section{Conclusion}

In conclusion, this study reveals hot spots and frontier issues in the field of acupuncture for pain. The findings presented here are expected to promote the optimization of treatment options. The frontier issues in the field presented here will guide funding organizations to refocus their funding priorities.

\section{Abbreviations}

C\&AT, complementary and alternative therapies; LLR, logarithmic likelihood ratio; KOA, knee osteoarthritis.

\section{Data Sharing Statement}

The following information was supplied regarding data availability: the raw data can be directly obtained from the Web of Science Core Collection (WoSCC) of Thomson Reuters.

\section{Acknowledgment}

Thanks to Prof. Chaomei Chen for opening the use of CiteSpace.

\section{Author Contributions}

All authors made substantial contributions to conception and design, acquisition of data, or analysis and interpretation of data; took part in drafting the article or revising it critically for important intellectual content; agreed to submit to the current journal; gave final approval of the version to be published; and agree to be accountable for all aspects of the work.

\section{Funding}

This study was supported by the National Natural Science Foundation of China (no. 81673887), the National Science and Technology Support Program of the ministry of science and technology of China (2013BAI05B00), the Science and technology innovation capacity cultivation project of Shanxi University of Traditional Chinese Medicine (2020PY-LP-03). The funders had no role in study design, data collection and analysis, decision to publish, or preparation of the manuscript.

\section{Disclosure}

The authors declare that they have no conflicts of interest for this work.

\section{References}

1. Pergolizzi J, Ahlbeck K, Aldington D, et al. The development of chronic pain: physiological CHANGE necessitates a multidisciplinary approach to treatment. Curr Med Res Opin. 2013;29(9):1127-1135. doi:10.1185/03007995.2013.810615

2. Langley PC. The prevalence, correlates and treatment of pain in the European Union. Curr Med Res Opin. 2011;27(2):463-480. doi:10.1185/03007995.2010.542136

3. Gaskin DJ, Richard P. The economic costs of pain in the United States. J Pain. 2012;13(8):715-724. doi:10.1016/j.jpain.2012.03.009

4. Cohen SP, Hooten WM. Advances in the diagnosis and management of neck pain. BMJ. 2017;358:j3221. doi:10.1136/bmj.j3221

5. Vickers AJ, Cronin AM, Maschino AC, et al. Acupuncture for chronic pain: individual patient data meta-analysis. Arch Intern Med. 2012;172 (19):1444-1453. doi:10.1001/archinternmed.2012.3654

6. Zhao ZQ. Neural mechanism underlying acupuncture analgesia. Prog Neurobiol. 2008;85(4):355-375.

7. Haake M, Müller HH, Schade-Brittinger C, et al. German Acupuncture Trials (GERAC) for chronic low back pain: randomized, multicenter, blinded, parallel-group trial with 3 groups. Arch Intern Med. 2007;167 (17):1892-1898. doi:10.1001/Archinte.167.17.1892

8. Zhang R, Lao L, Ren K, Berman BM. Mechanisms of acupuncture-electroacupuncture on persistent pain. Anesthesiology. 2014;120(2):482-503. doi:10.1097/ALN.0000000000000101

9. Cherkin DC, Sherman KJ, Avins AL, et al. A randomized trial comparing acupuncture, simulated acupuncture, and usual care for chronic low back pain. Arch Intern Med. 2009;169(9):858-866. doi:10.1001/archinternmed.2009.65

10. Molsberger AF, Schneider T, Gotthardt H, Drabik A. German Randomized Acupuncture Trial for chronic shoulder pain (GRASP) - a pragmatic, controlled, patient-blinded, multi-centre trial in an outpatient care environment. Pain. 2010;151(1):146-154. doi:10.1016/j.pain.2010.06.036

11. Harris RE, Zubieta JK, Scott DJ, Napadow V, Gracely RH, Clauw DJ. Traditional Chinese acupuncture and placebo (sham) acupuncture are differentiated by their effects on mu-opioid receptors (MORs). NeuroImage. 2009;47(3):1077-1085. doi:10.1016/j. neuroimage.2009.05.083 
12. Kietrys DM, Palombaro KM, Azzaretto E, et al. Effectiveness of dry needling for upper-quarter myofascial pain: a systematic review and meta-analysis. J Orthop Sports Phys Ther. 2013;43(9):620-634. doi:10.2519/jospt.2013.4668

13. Lee JH, Choi TY, Lee MS, Lee H, Shin BC, Lee H. Acupuncture for acute low back pain: a systematic review. Clin J Pain. 2013;29 (2):172-185. doi:10.1097/AJP.0b013e31824909f9

14. Li R, Sun J, Hu H, et al. Research trends of acupuncture therapy on knee osteoarthritis from 2010 to 2019: a bibliometric analysis. J Pain Res. 2020;13:1901-1913. doi:10.2147/JPR.S258739

15. Zhang W, Nuki G, Moskowitz RW, et al. OARSI recommendations for the management of hip and knee osteoarthritis: part III: changes in evidence following systematic cumulative update of research published through January 2009. Osteoarthritis Cartilage. 2010;18 (4):476-499. doi:10.1016/j.joca.2010.01.013
16. Ernst E, Lee MS, Choi TY. Acupuncture: does it alleviate pain and are there serious risks? A review of reviews. Pain. 2011;152 (4):755-764. doi:10.1016/j.pain.2010.11.004

17. MacPherson H, Altman DG, Hammerschlag R, et al. Revised STandards for Reporting Interventions in Clinical Trials of Acupuncture (STRICTA): extending the CONSORT statement. PLoS Med. 2010;7(6):e1000261. doi:10.1371/journal.pmed.1000261

18. Tu Y, Zeng F, Lan L, et al. An fMRI-based neural marker for migraine without aura. Neurology. 2020;94(7):e741-e751. doi:10.1212/WNL.0000000000008962

19. Tu JF, Yang JW, Shi GX, et al. Efficacy of intensive acupuncture versus sham acupuncture in knee osteoarthritis: a randomized controlled trial. Arthritis Rheum. 2020.

\section{Publish your work in this journal}

The Journal of Pain Research is an international, peer reviewed, open access, online journal that welcomes laboratory and clinical findings in the fields of pain research and the prevention and management of pain. Original research, reviews, symposium reports, hypothesis formation and commentaries are all considered for publication. The manuscript management system is completely online and includes a very quick and fair peer-review system, which is all easy to use. Visit http:// www.dovepress.com/testimonials.php to read real quotes from published authors. 